\title{
Importance of Experimental Tests for the Determination of Modeling Parameters in Fire Safety Engineering
}

\author{
Vincenzo Torretta ${ }^{l}$, Marco Barozzi ${ }^{2}$, Luca Talamona ${ }^{l}$, Sabrina Copelli ${ }^{2}$, Fabio Conti ${ }^{l}$, \\ Elena Cristina Rada ${ }^{l}$, Paolo Viotti ${ }^{3}$, and Marco Schiavon ${ }^{4}$ \\ ${ }^{1}$ Department of Theoretical and Applied Sciences, Insubria University, Via Vico, 46 - 21100, Varese, \\ Italy \\ ${ }^{2}$ Department of Sciences and High Technology, Insubria University, Via Vico, 46 - 21100, Varese, \\ Italy \\ ${ }^{3}$ Department of Civil, Building and Environmental Engineering (DICEA), Sapienza University of \\ Rome, Via Eudossiana 18 - 00184, Rome, Italy \\ ${ }^{4}$ Department of Civil Environmental and Mechanical Engineering, University of Trento, via Mesiano \\ 77, 38123, Trento, Italy
}

\begin{abstract}
In the field of Fire Safety Engineering, the application of mathematical models is crucial in order to properly estimate the severity of eventual fires occurring inside workplaces. Such models (like CFast, Ozone, FDS, CFX, Fluent), require a notable amount of specific parameters in order to work. Such parameters are usually available in the current literature, or they can be estimated via experimental tests. In this work, several experimental setups have been performed in order to evaluate such data in the burning of a wide range of materials: cotton, polyethylene and polyester in industrial rollers, flour, sugar, feed for dairy cows, and wood pallets. Cone Calorimeter, Mahler bomb, and real-scale tests have been performed in order to evaluate parameters such as Calorific Values, Total Heat Released, Heat Released Rate and smoke composition analysis. The real-scale tests have been performed with the aim of addressing fire occurring in warehouses, focusing then on an industrial environment. All the values have been compared with theoretical estimations made with the ClaRaf 2.0 software, and it was noticed that they tend to give overestimated values in comparison with empirical results.
\end{abstract}

\section{Introduction}

Fires are for decades among the worst and most common accidents around the world, involving both civil and industrial life [1-4]. Prevention and protection from such events have been and are still target of research and interest [5-13]. In the field of Fire Safety Engineering, a proper fire risk assessment requires specific chemical-physical parameters about the material that could potentially ignite and information about how and under which condition the same material is stored and treated. In this sense, warehouses represent an interesting context for fire safety issues $[8,14]$. Over a wide set of combustible materials, the Calorific Values, Total Heat Released (THR) and the Rate of Heat Released (RHR) 
have been experimentally evaluated through tests according to international standards. Such values have been compared with estimates available on well-known databases, and with theoretical values determined with the ClaRaf 2.0 software [15-19]. It was noticed that such values may be consistently different. In addition, real-scale tests have been performed, in order to study the severity of a fire that can occur inside warehouses, hence focusing on an industrial environment. Warehouses have the potential of bringing to severe accidents, due to the amount of material stored.

This paper presents several experimental setups that have been performed to evaluate specific parameters in the burning of a wide range of materials: cotton, polyethylene and polyester in industrial rollers, flour, sugar, feed for dairy cows, and wood pallets. The results will show that performing ad hoc experiments can lead to valuable knowledge and data, that can be used in order to implement mathematical simulations (like CFast, Ozone, FDS, CFX, Fluent) and fire risk assessment protocols.

\section{Materials and methods}

The first tests have been performed on industrial cotton rollers. For what concerns smallscale tests, Mahler Bomb (according to standard ISO 1716 [20]) was used for the determination of the higher heating value (HHV). A Cone Calorimeter (according to standard EN ISO 5660 [21]) test was also carried out for the determination of the THR. Several experiments were accomplished at a more realistic scale, by burning industrial cotton rollers under the hood of the Room Corner Test (according to the standard ISO 9705 [22]). Table 1 lists the characteristics of a single cotton roller.

Table 1. Properties of a cotton roller

\begin{tabular}{|l|l|}
\hline Cotton density & $110 \mathrm{~g} / \mathrm{m}^{3}$ \\
\hline Specific weight of rolled cotton & $547 \mathrm{~kg} / \mathrm{m}^{3}$ \\
\hline Color & White \\
\hline Linear weight & $179.3 \mathrm{~g} / \mathrm{m}$ \\
\hline Number of layers & 1012 \\
\hline Single layer thickness & $0.20 \mathrm{~mm}$ \\
\hline Roller length & $1530 \mathrm{~mm}$ \\
\hline Total roller weight & $209.33 \mathrm{~kg}$ \\
\hline Cotton only weight & $182.33 \mathrm{~kg}$ \\
\hline Total cotton surface & $1657.54 \mathrm{~m}^{2}$ \\
\hline
\end{tabular}

Firstly, a single roller was burned, using the ignition model 5 of EN 45545-1 standard [23], which accounts for the most severe fire scenario. Three tests have been performed under the same conditions. In addition, in order to represent a realistic warehouse, an additional test has been carried out by using three cotton rollers, displaced as indicated in Fig. 1.

A similar study was done on plastic film rollers, made of polyethylene, polyester and a special material made of several aluminum and polymer layers. The characteristics of the rollers involved are listed in Table 2. Such materials are commonly used for food packaging. As above, Mahler Bomb [20] and Cone Calorimeter [21] have been used for small-scale tests. For real-case tests, the Room Corner Test [22] has been applied, again according to the ignition model 5 of EN 45545-1 standard [23]. In this case, it was necessary to modify the ignition source, since the melted plastic material would compromise the execution of the test. It was hypothesized the leakage of ethyl acetate, 
which is used in the production line of these plastic films. Experimental tests have been performed with a single roller, and two rollers, as shown in Fig. 2.

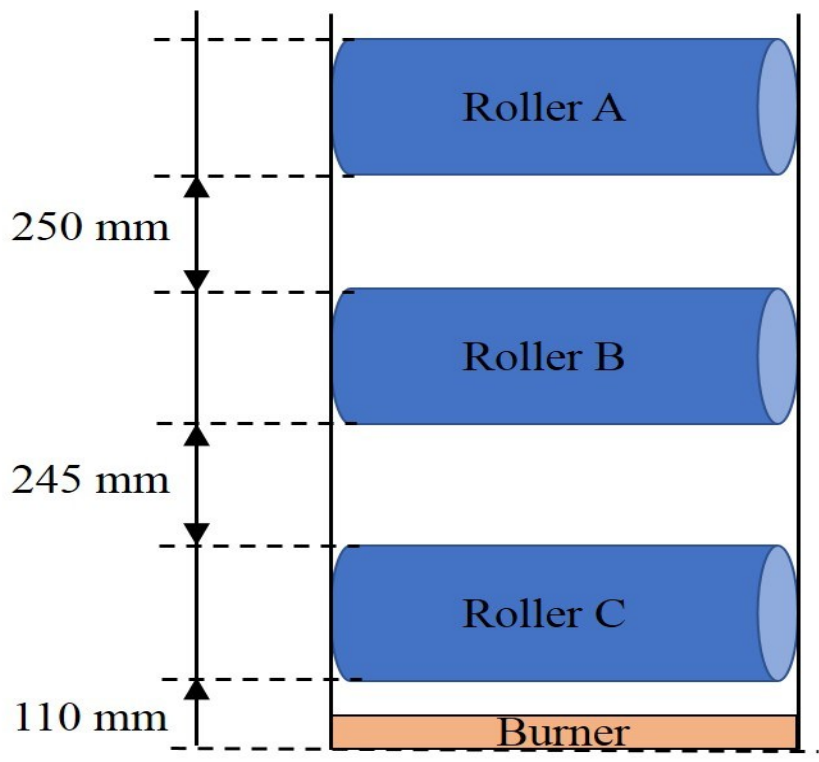

Fig. 1. Rollers disposition for the real-scale test (cotton)

Table 2. Properties of polymeric rollers.

\begin{tabular}{|l|l|l|l|}
\hline & Polyethylene & Polyester & Mixed \\
\hline Specific weight & $830 \mathrm{~kg} / \mathrm{m}^{3}$ & $750 \mathrm{~kg} / \mathrm{m}^{3}$ & $978 \mathrm{~kg} / \mathrm{m}^{3}$ \\
\hline Roller width & $260 \mathrm{~mm}$ & $260 \mathrm{~mm}$ & $260 \mathrm{~mm}$ \\
\hline Roller length & $2230 \mathrm{~mm}$ & $2230 \mathrm{~mm}$ & $2230 \mathrm{~mm}$ \\
\hline Total roller weight & $2402 \mathrm{~kg}$ & $2170 \mathrm{~kg}$ & $2349 \mathrm{~kg}$ \\
\hline
\end{tabular}

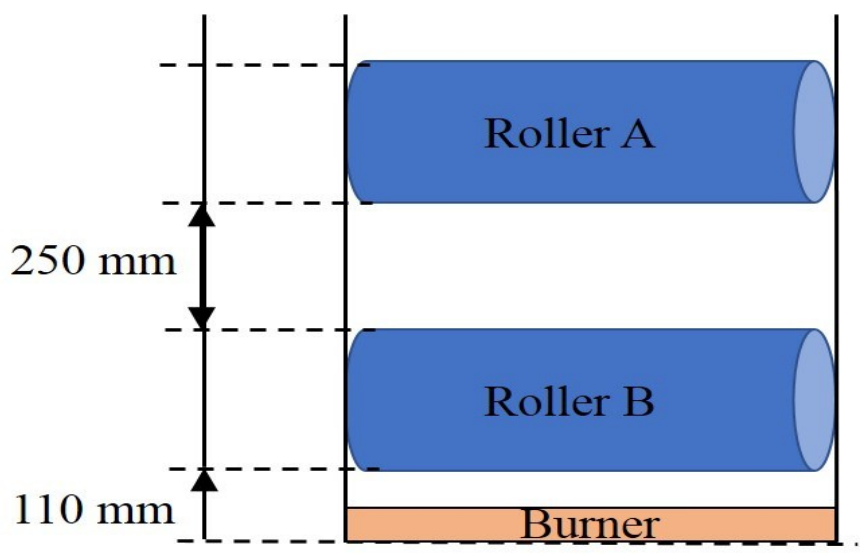

Fig. 2. Rollers disposition for the real-scale test (polymers)

The same study was accomplished for powdered foods. Fires involving flour, feed for dairy cows, feed for laying hens, wheat bran, corn, and rye bread stored in warehouses have been investigated. With the target of identifying an industrial case, two scenarios have been 
considered: the triggering of a stack of products (as shown in Fig. 3A), and the fire of a pile of wood load pallets (see Fig. 3B). Each stack of products is made of 25-33 bags of about $20-25 \mathrm{~kg}$ each, with a total weight for a single stack about $850 \mathrm{~kg}$. The wood stack is made of 10 pallets, each one is $25 \mathrm{~kg}$ heavy, and the total height of the stack is $144 \mathrm{~cm}$.

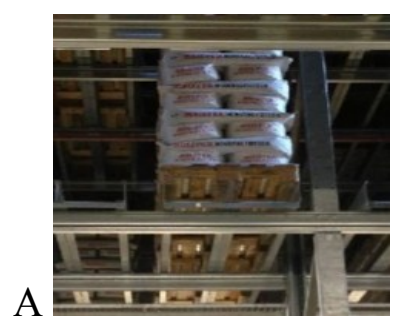

$\mathrm{B}$

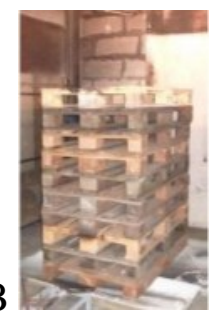

Fig. 3. A Flour stack used for the real-scale test (total weight $850 \mathrm{~kg}$ ). B Wood pallets used for the real-scale test (total weight $(250 \mathrm{~kg})$

The packaging of such goods was also the subject of small-scale tests, in order to evaluate if it should be considered in fire safety assessments. Table 3 collects all the characteristics of the considered foods. Rye bread information was not reported, since it is unimportant for this study.

Table 3. Properties of the powdered foods

\begin{tabular}{|l|l|l|l|l|l|}
\hline & $\begin{array}{c}\text { Wheat } \\
\text { flour }\end{array}$ & $\begin{array}{c}\text { Feed for } \\
\text { dairy cows } \\
\text { (pellets) }\end{array}$ & $\begin{array}{c}\text { Feed for } \\
\text { laying hens } \\
\text { (pellets) }\end{array}$ & $\begin{array}{c}\text { Wheat } \\
\text { bran }\end{array}$ & Corn \\
\hline Moisture & $15.5 \%$ & & & & \\
\hline Proteins & & $18.0 \%$ & $18.0 \%$ & $16.6 \%$ & \\
\hline Cellulose & & $7.5 \%$ & $3.0 \%$ & $12.0 \%$ & \\
\hline Oils and fats & & $3.2 \%$ & $5.0 \%$ & $5.0 \%$ & \\
\hline Ashes & & $5.0 \%$ & $12.0 \%$ & & \\
\hline Sodium & & $0.3 \%$ & $0.18 \%$ & & \\
\hline Calcium & & & $3.7 \%$ & & \\
\hline Phosphorus & & & $0.60 \%$ & & \\
\hline Methionine & & & $0.42 \%$ & & \\
\hline Lysine & & & $0.82 \%$ & & \\
\hline Starch & & & & $14.5 \%$ & \\
\hline Dimensions & & $6 \times 20 \mathrm{~mm}$ & $4 \mathrm{~mm}$ & $1 \mathrm{~mm}$ & $6 \mathrm{~mm}$ \\
\hline
\end{tabular}

Each material ribbon type has been tested with the Cone Calorimeter. For the real case tests, a triggering model based upon the standard EN 50399 [24] was implemented. Hence, a premixed air-propane burner was used, with a thermal power equal to $30 \mathrm{~kW}$ for the first 2 minutes, followed by a power of $50 \mathrm{~kW}$ in the following 8 minutes of the test.

Finally, the combustion of white sugar was studied. Cone Calorimeter tests have been performed for the determination of Calorific Values. For the real case tests, two scenarios have been investigated. First, a polypropylene bag containing $1000 \mathrm{~kg}$ of sugar (Fig. 4A) has been set afire under the hood of the Room Corner Test. The triggering of the sugar bag always followed the standard EN 50399 [24] for the burner. Secondly, another fire test has been made with a stack made of 21 sugar sack of $25 \mathrm{~kg}$ each (see Fig. 4B). 

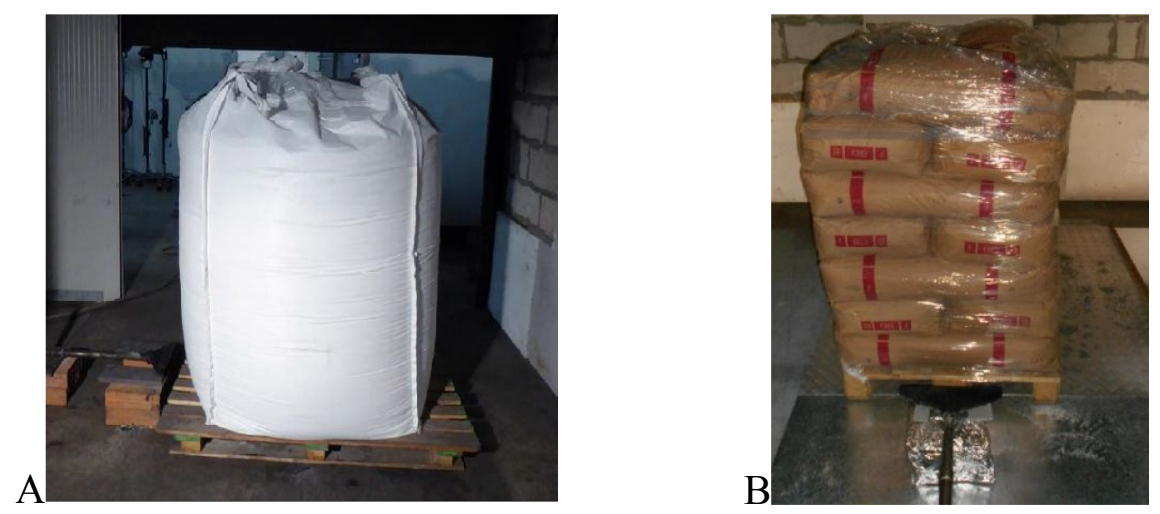

Fig. 4. A: Polypropylene bag containing $1000 \mathrm{~kg}$ of sugar. B: Stack of 21 sugar sacks (total sugar $1000 \mathrm{~kg}$ )

\section{Results and discussion}

\subsection{Cotton rollers}

Table 4 shows the results for the heating values for cotton. The HHV has been estimated through the software ClaRaf 2.0, through the Mahler Bomb and the Cone Calorimeter.

Table 4. Comparison among the HHVs for cotton (* average of three tests)

\begin{tabular}{|l|l|l|l|}
\hline & ClaRaf 2.0 & Mahler Bomb* & Cone Calorimeter* \\
\hline Cotton & $20 \mathrm{MJ} / \mathrm{kg}$ & $15.35 \mathrm{MJ} / \mathrm{kg}$ & $9.42 \mathrm{MJ} / \mathrm{kg}$ \\
\hline
\end{tabular}

With the Cone Calorimeter, it is possible to evaluate the effect of different levels of stretching and compactness of cotton (due to the roller). Fig. 5 shows that compacted cotton (red line), leads to lower values of the THR (7\% lower). This is due to the fact that highly compacted material do not completely take part in the combustion process.

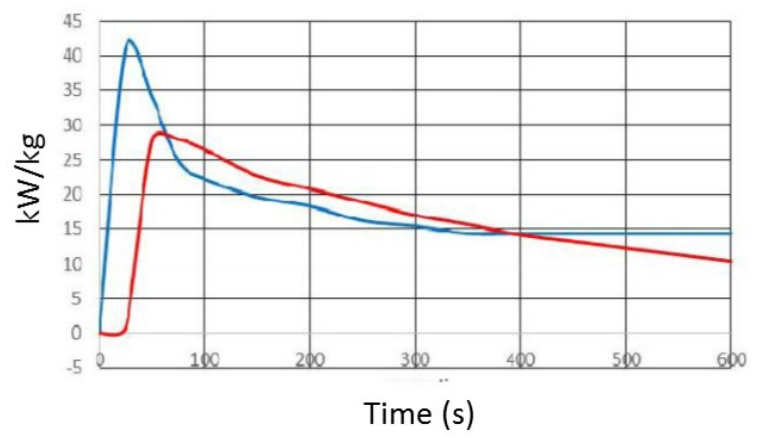

Fig. 5. THR in different Cone Calorimeter setups. In blue, we have a not compact cotton sample, in red we have a compact cotton sample. The integral area (which is the Released Heat), is 7\% lower for the compacted cotton.

Real-scale tests were performed under the hood of the Room Corner Test. The characteristics of the room and ignition are the following:

- Room dimensions: $2.4 \times 3.6 \times 2.4 \mathrm{~m}$

- Door dimensions: $2.0 \times 0.8 \mathrm{~m}$ 
- Propane burner: 17 x 17 x $30 \mathrm{~cm}$

The system is also provided with smoke collection and analysis. For the ignition, the ignition model 5 of EN 45545-1 standard [23] was applied. Under such conditions, we have a 10 mins test, where, for the first 120 seconds, the ignitors have a power of $75 \mathrm{~kW}$, increased to $150 \mathrm{~kW}$ for the rest of the time (step-like increment). The total thermal energy due to ignitors has been estimated around $81 \mathrm{MJ}$ for the whole test. According to ClaRaf 2.0 software, this energy is comparable to $2.5 \mathrm{~L}$ of gasoline. three tests with a single cotton roller have been performed, and the results are reported in Table 5 . We can notice that the average mass involved is equal to $3.76 \%$ of the total mass, indicating that a very small portion of the roller participates in the process. We also report in Fig. 6 the Released Heat Rate for these tests.

Table 5. Results of the combustion of a cotton roller under the hood of the Room Corner Test

\begin{tabular}{|l|c|c|c|c|}
\hline & THR(900s) $[\mathrm{MJ}]$ & Mass loss $[\mathrm{kg}]$ & Specific THR [MJ/kg] & Mass loss over time [g/s] \\
\hline Test 1 & 44 & 7.32 & 6.01 & 8.13 \\
\hline Test 2 & 44 & 6.26 & 7.02 & 6.95 \\
\hline Test 3 & 57 & 6.76 & 8.34 & 7.48 \\
\hline Average & 48.3 & 6.77 & 7.12 & 7.52 \\
\hline
\end{tabular}

A
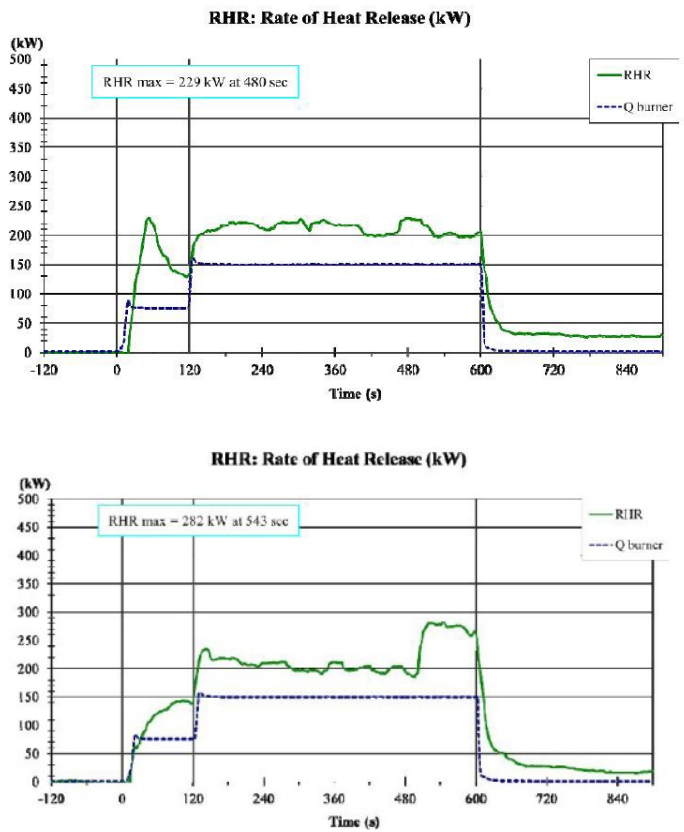

B

RHR: Rate of Heat Release (kW)

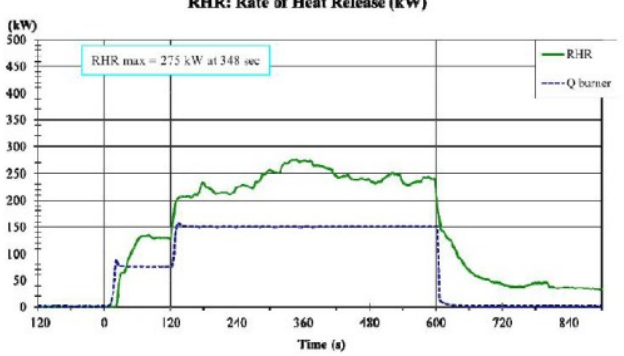

Fig. 6. Rate of Heat Release for a single cotton roller. (A: Test 1, B: Test 2, C: Test 3) 
In order to account for a more realistic industrial situation, another test was carried by considering three cotton rollers positioned vertically. The results where interesting: the upper roller (3), was basically untouched in the test, as it is possible to see in Fig. 7. Table 6 reports the results of the test.

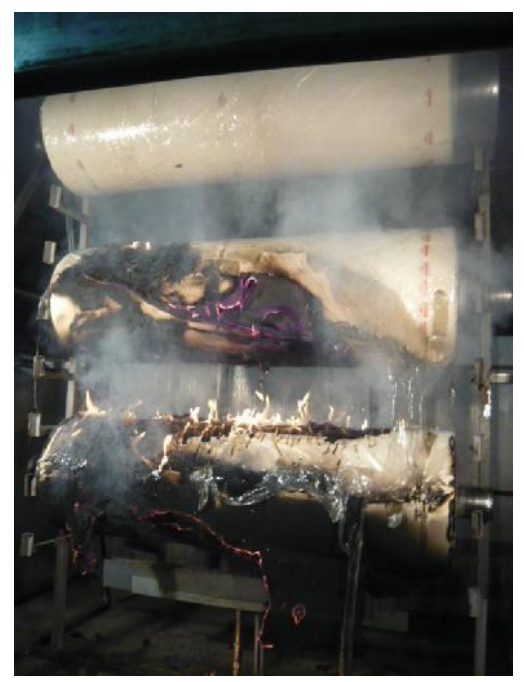

Fig. 7. Cotton rollers after the real scale test (starting from below: roller 1, 2, 3)

Table 6. Results of the combustion of three cotton rollers under the hood of the Room Corner Test

\begin{tabular}{|l|c|c|c|c|}
\hline & THR (900s) [MJ] & Mass loss [kg] & $\begin{array}{l}\text { Specific THR } \\
{[\mathrm{MJ} / \mathrm{kg}]}\end{array}$ & $\begin{array}{l}\text { Mass loss over time } \\
{[\mathrm{g} / \mathrm{s}]}\end{array}$ \\
\hline Roller 1 & 55 & 11.61 & 4.76 & 12.90 \\
\hline Roller 2 & 40 & 8.32 & 4.76 & 9.24 \\
\hline Roller 3 & 0 & 0 & 0 & 0 \\
\hline Total & 95 & 19.93 & 4.76 & 22.14 \\
\hline
\end{tabular}

From the results of the tests, we can offer a comparison between the heat released from a cotton roller. According to small-scale tests, we have an estimation of $3600 \mathrm{MJ}$ (ClaRaf 2.0), $2763 \mathrm{MJ}$ (Mahler bomb), and $1695 \mathrm{MJ}$ (Cone calorimeter). The lower value from the Cone Calorimeter is due to the fact that the test does not consider the contribution of smoke.

If we consider the Cone Calorimeter as the baseline, we obtain for the burned rollers (including all the tests), heat percentages lower than $4 \%$ (2.84\% for single roller burned, $3.24 \%$ for roller A and $2.35 \%$ for roller B). In this sense, we can notice that experimental values bring to significant lower energies if compared to pure theoretical models (that impose total combustion).

\subsection{Polyethylene and polyester rollers}

In this case, industrial rollers of polyethylene, polyester, and a special mixed material (containing both polymers and aluminum layers, nylon and glass fiber). Small-scale tests have been performed for the determination of the Calorific Values. The results have been compared with theoretical estimations with ClaRaf 2.0, as shown in Table 7. 
Table 7. Comparison among Calorific Vales for polymers (* average of three tests)

\begin{tabular}{|l|l|l|l|}
\hline & ClaRaf 2.0 & Mahler bomb* & Cone Calorimeter* \\
\hline Polyethylene & $40.0 \mathrm{MJ} / \mathrm{kg}$ & $46.66 \mathrm{MJ} / \mathrm{kg}$ & $19.40 \mathrm{MJ} / \mathrm{kg}$ \\
\hline Polyester & $30.0 \mathrm{MJ} / \mathrm{kg}$ & $22.24 \mathrm{MJ} / \mathrm{kg}$ & $17.81 \mathrm{MJ} / \mathrm{kg}$ \\
\hline Mixed & N.A. & $39.98 \mathrm{MJ} / \mathrm{kg}$ & $37.69 \mathrm{MJ} / \mathrm{kg}$ \\
\hline
\end{tabular}

It was interesting to notice that, in the case of the mixed polymer, a smaller part of mass contributed to the Cone Calorimeter test in comparison with other tests, despite being composed by the same materials.

For the real scale test, the Room Corner Test hood and exhaust duct have been used. The burner was implemented with the same conditions as the cotton rollers. Under such conditions, the test could not be performed properly: the melted polymer layers would block the process. It was necessary to introduce a specific triggering system, represented by leakage of ethyl acetate, which is a potential accident in an industrial environment. $2.5 \mathrm{~L}$ ethyl acetate were displaced in a steel tray at the bottom of the room, with a dimension of $140 \times 70 \mathrm{~cm}$. The thickness of the ethyl acetate was around $2.5 \mathrm{~mm}$. Also, 4 liters of water were placed in the same tray, in order to make the surface more homogenous, and prevent excessive deformation of the tray during the combustion. The system had to be specifically calibrated, by performing tests with ethyl acetate only. After this test, the thermal power due to this additional trigger was estimated to be about $55 \mathrm{MJ}$. In order to simplify the procedure, lighter rollers were used. Instead of using about $2400 \mathrm{~kg}$ for a single roller, 512 $\mathrm{kg}$ rollers, with an external diameter of $600 \mathrm{~mm}$ were used in all the experiments. All the results of the tests with a single roller are reported in Table 8.

Table 8. Results of the combustion of a single polymer roller under the hood of the Room Corner

\begin{tabular}{|c|c|c|c|c|}
\hline \multicolumn{5}{|c|}{ Test } \\
\hline & $\begin{array}{c}\text { THR (360 s) } \\
{[\mathrm{MJ}]}\end{array}$ & $\begin{array}{c}\text { THR (360 s) } \\
\text { without trigger } \\
{[\mathrm{MJ}]}\end{array}$ & $\begin{array}{c}\text { Mass loss } \\
{[\mathrm{kg}]}\end{array}$ & $\begin{array}{c}\text { Specific THR } \\
{[\mathrm{MJ} / \mathrm{kg}]}\end{array}$ \\
\hline \multicolumn{5}{|c|}{ Polyethylene } \\
\hline Test 1A & 115.7 & 60.7 & 3.12 & 19.4 \\
\hline Test 2A & 110.7 & 64.7 & 3.33 & 19.4 \\
\hline Test 3A & 120.3 & 65.3 & 3.36 & 19.4 \\
\hline Test 4A & 120.1 & 65.1 & 3.35 & 19.4 \\
\hline Test 5A & 85.4 & 30.4 & 1.56 & 19.4 \\
\hline Test 6A & 108.2 & 53.2 & 2.74 & 19.4 \\
\hline Average (1-4) & 118.95 & 63.95 & 3.29 & 19.4 \\
\hline \multicolumn{5}{|c|}{ Polyester } \\
\hline Test 1B & 279.6 & 221.6 & 12.9 & 17.81 \\
\hline Test 2B & 127.1 & 72.1 & 4.14 & 17.81 \\
\hline Test 3B & 126.0 & 71.0 & 4.08 & 17.81 \\
\hline Test 4B & 188.1 & 133.1 & 7.64 & 17.81 \\
\hline Average & 147.07 & 92.07 & 5.29 & 17.81 \\
\hline \multicolumn{5}{|c|}{ Mixed } \\
\hline Test $1 \mathrm{C}$ & 127.3 & 72.3 & 1.91 & 37.69 \\
\hline Test 2C & 132.7 & 77.7 & 2.06 & 37.69 \\
\hline Test 3C & 149.9 & 94.9 & 2.57 & 37.69 \\
\hline Average & 147.07 & 81.6 & 2.16 & 37.69 \\
\hline
\end{tabular}

It is interesting to see that, in the case of polyethylene, Test $5 \mathrm{~A}$ and $6 \mathrm{~A}$ brought to unusual results, hence they were not considered in the computation of the mean values. 
Polyester combustion is different from polyethylene, and the results are quite variable. For the mixed material it was confirmed that it tends to burn a lower amount of mass. According to the mass lost, $0.58 \%, 1.03 \%$ and $0.42 \%$ of the total mass where involved in the combustion, for polyethylene, polyester and mixed material respectively. Fig. 8 shows the rollers after the test.
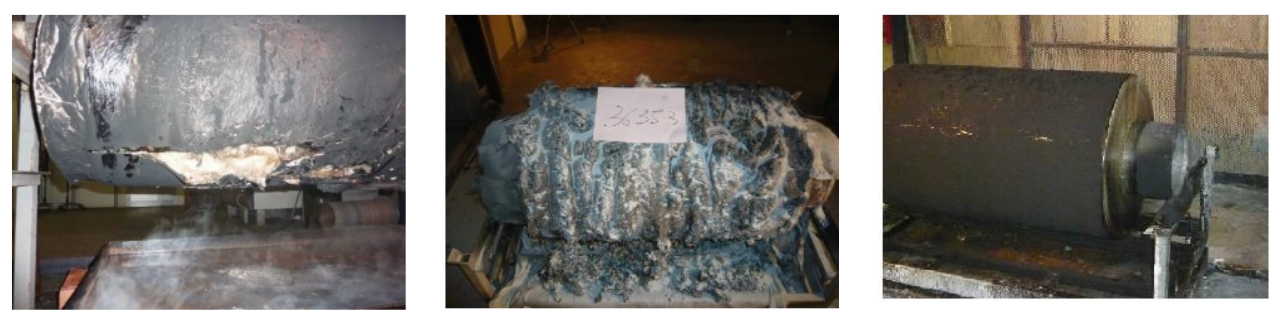

Fig. 8. Polymer rollers after the real scale test (from left to right: polyethylene, polyester, mixed)

In addition, tests with two vertically placed rollers where carried out using polyethylene and mixed material. Polyester was not considered, due to the unreliable results from the real scale test. In the case of polyethylene, the upper roller was not involved in the combustion, as shown in Fig. 9. With the mixed material, the process is more homogeneous, and both rollers were set afire. Table 9 reports the results of the experiments.
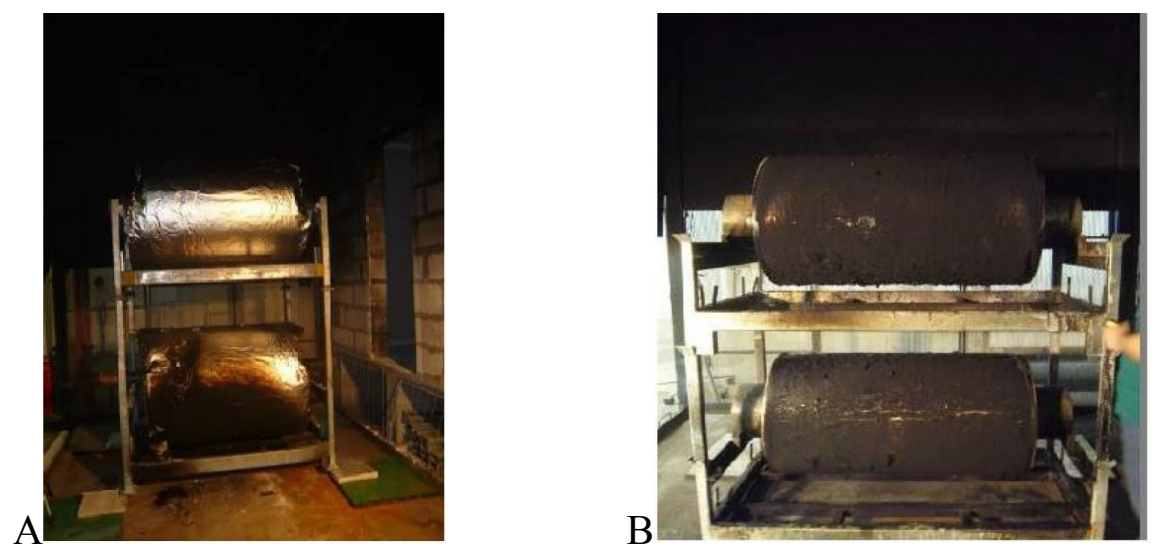

Fig. 9. Polymer rollers after the Room Corner Test with 2 samples (A: polyethylene, B: mixed material)

It is interesting to compare the heat released from each roller by using different approaches. In the case of the real scale test, the heat has been calculated proportionally to the mass used in the test $(512 \mathrm{~kg})$.

Table 9. Results of the combustion of two polymer rollers under the Room Corner Test hood

\begin{tabular}{|l|c|l|l|c|}
\hline & $\begin{array}{l}\text { THR (360 s) } \\
{[\mathrm{MJ}]}\end{array}$ & $\begin{array}{l}\text { THR (360 s) triggering } \\
\text { only [MJ }]\end{array}$ & $\begin{array}{l}\text { Mass loss } \\
{[\mathrm{kg}]}\end{array}$ & $\begin{array}{l}\text { Specific THR } \\
{[\mathrm{MJ} / \mathrm{kg}]}\end{array}$ \\
\hline \multicolumn{5}{|c|}{ Polyethylene } \\
\hline Roller A & 114.5 & 59.6 & 3.12 & 19.4 \\
\hline \multicolumn{4}{|c|}{ Mixed } \\
\hline $\begin{array}{l}\text { Roller A } \\
\text { and B }\end{array}$ & 175.8 & 120.8 & 3.20 & 37.69 \\
\hline
\end{tabular}


Table 10. Results of the combustion of two polymer rollers under the Room Corner Test hood

\begin{tabular}{|l|c|c|c|c|c|}
\hline & $\begin{array}{c}\text { Roller } \\
\text { Mass }\end{array}$ & \multicolumn{4}{|c|}{ Heat released [MJ] } \\
\cline { 2 - 6 } & {$[\mathrm{kg}]$} & $\begin{array}{c}\text { ClaRaf } \\
2.0\end{array}$ & $\begin{array}{c}\text { Mahler } \\
\text { bomb }\end{array}$ & $\begin{array}{c}\text { Cone } \\
\text { Calorimeter }\end{array}$ & $\begin{array}{c}\text { Room Corner } \\
\text { Test }\end{array}$ \\
\hline Polyethylene & 2402 & 96000 & 111840 & 46560 & 299.76 \\
\hline Polyester & 2170 & 65100 & 48260 & 38647 & 390.21 \\
\hline Mixed & 2349 & N.A. & 93725 & 88533 & 374.37 \\
\hline
\end{tabular}

Such discrepancies bring to extremely different results in the application of fire safety protocols, since the heat that is effectively released during a real test is sensibly lower than the result of conservative estimations.

\subsection{Flour, feed, corn and rye bread}

In this part, several powdered foods have been investigated. The HHV was estimated through Cone Calorimeter testing. All the samples were prepared including a portion of packaging, in order to include it in the heat released estimation. Table 11 reports the results.

Table 11. Comparison among Calorific Vales for powdered food (* average of three tests)

\begin{tabular}{|c|c|c|c|c|c|}
\hline & $\begin{array}{c}\text { Wheat } \\
\text { flour }\end{array}$ & $\begin{array}{c}\text { Feed for } \\
\text { dairy cows } \\
\text { (pellets) }\end{array}$ & $\begin{array}{c}\text { Feed for } \\
\text { laying hens } \\
\text { (pellets) }\end{array}$ & $\begin{array}{c}\text { Wheat } \\
\text { bran }\end{array}$ & Corn \\
\hline $\begin{array}{c}\mathrm{HHV} \\
(\text { Cone Calorimeter*) } \\
{[\mathrm{MJ} / \mathrm{kg}]}\end{array}$ & 1.39 & 1.65 & 1.41 & 1.67 & 1.46 \\
\hline
\end{tabular}

For the real-scale tests, stacks of materials have been used under the hoof of the Room Corner Test. The stacks have been arranged in a steel structure, shown in Fig. 10, which represents a real industrial warehouse.

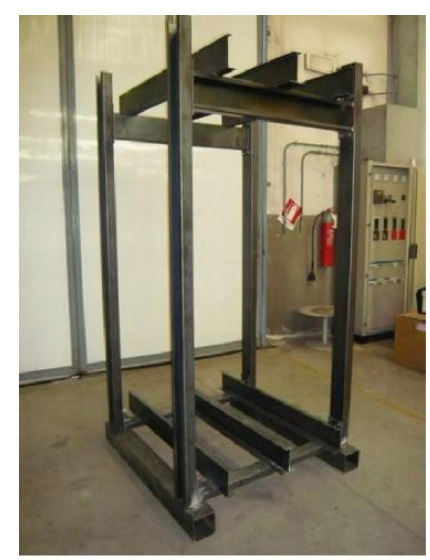

Fig. 10. Steel structure used to contain the food stacks.

The structure of the different stacks is reported in Table 12. In some cases, tests with 2 stacks have been carried out. 
Table 12. Stacks compositions (the total weight accounts for the wood pallet at the bottom, for additional $25 \mathrm{~kg}$ )

\begin{tabular}{|c|c|c|c|c|}
\hline & $\begin{array}{c}\text { Wheat } \\
\text { flour }\end{array}$ & $\begin{array}{c}\text { Feed for } \\
\text { dairy cows } \\
\text { (pellets) }\end{array}$ & $\begin{array}{c}\text { Rye } \\
\text { bread }\end{array}$ & $\begin{array}{c}\text { Wood } \\
\text { pallets } \\
\text { only }\end{array}$ \\
\hline Total bags & 25 & 25 & 80 & 10 \\
\hline $\begin{array}{c}\text { Total } \\
\text { weight }[\mathrm{kg}]\end{array}$ & 850 & 850 & 325 & 250 \\
\hline
\end{tabular}

The ignition conditions are in accordance with EN 50399 [20] with different power outputs: $30 \mathrm{~kW}$ for the first 2 minutes, and $50 \mathrm{~kW}$ for the other 8 minutes (step-like increase). Under such conditions, the thermal power for the burner is equal to $27.6 \mathrm{MJ}$. For simplicity, we report the average net THR and the maximum RHR for all the tests and performed in Table 13.

Table 13. THR and maximum RHR for different stacks burned $\left({ }^{a}\right.$ : average of two tests ${ }^{b}$ :test performed with 2 stacks)

\begin{tabular}{|c|c|c|c|c|}
\hline & $\begin{array}{c}\text { Wheat } \\
\text { flour }^{\mathrm{a}}\end{array}$ & $\begin{array}{c}\text { Feed for } \\
\text { diary cows }^{\text {(pellets) }}\end{array}$ & $\begin{array}{c}\text { Rye } \\
\text { bread }^{\mathrm{b}}\end{array}$ & $\begin{array}{c}\text { Wood } \\
\text { pallets } \\
\text { only }\end{array}$ \\
\hline $\begin{array}{c}\text { THR } \\
(900 \mathrm{~s}) \\
{[\mathrm{MJ}]}\end{array}$ & 23.05 & 41.8 & 29 & $\begin{array}{c}1954 \\
(3600 \mathrm{~s})\end{array}$ \\
\hline $\begin{array}{c}\text { RHR peak } \\
{[\mathrm{kW}]}\end{array}$ & 109 & 165 & 52 & 1956 \\
\hline
\end{tabular}

\subsection{Sugar}

Finally, white sugar was studied. Table 14 reports a comparison between theoretical estimations and Cone Calorimeter tests.

Table 14. Comparison among Calorific Vales for sugar (* average of two tests)

\begin{tabular}{|l|l|l|}
\hline & HHV - ClaRaf 2.0 & HHV - Cone Calorimeter* \\
\hline Sugar & $17 \mathrm{MJ} / \mathrm{kg}$ & $12.25 \mathrm{MJ} / \mathrm{kg}$ \\
\hline
\end{tabular}

In this case, two different storage options were investigated: a single polypropylene bag of $1000 \mathrm{~kg}$ of sugar, and a stack made of 21 sacks of sugar (total mass of sugar $1000 \mathrm{~kg}$ ). The ignition conditions are again in accordance with EN 50399 [20] with modified power outputs: $30 \mathrm{~kW}$ for the first 2 minutes, and $50 \mathrm{~kW}$ for the other 8 minutes (step-like increase). Under such conditions, the thermal power for the burner is equal to $27.6 \mathrm{MJ}$.

Figure 11 reports the RHR, THR and transmittance of the test performed. Fig.12 shows some picture of the experiment during the sugar combustion. 


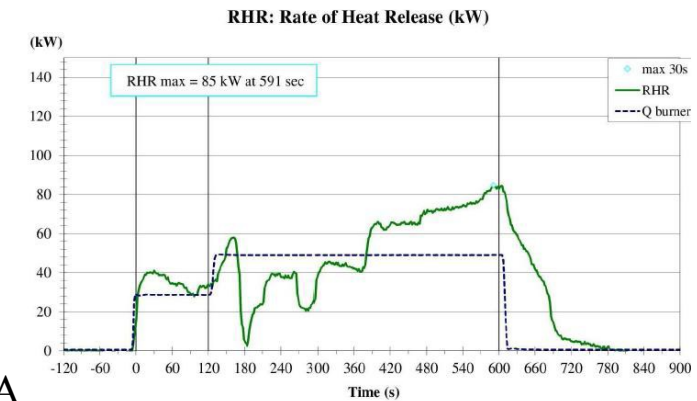

A

THR: Total Heat Relase (M.J)

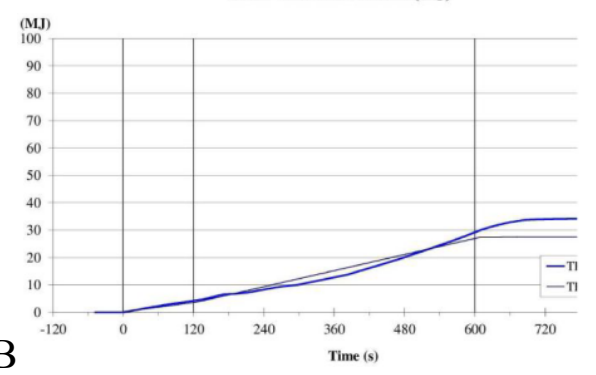

Transmittance $(\%)$

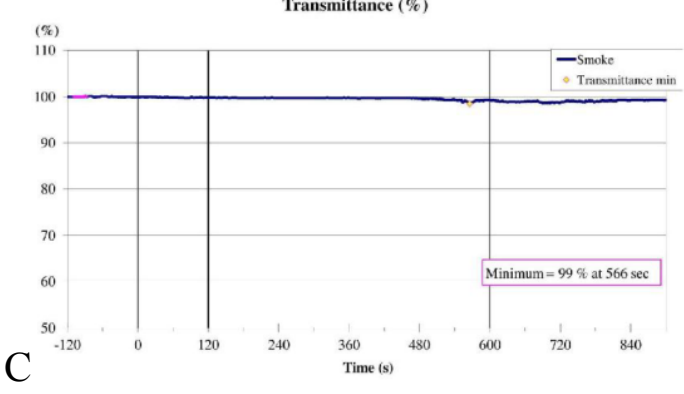

Fig. 11. Results of the real scale test for the $1000 \mathrm{~kg}$ sugar bag (A: RHR, B: THR, C: Transmittance)

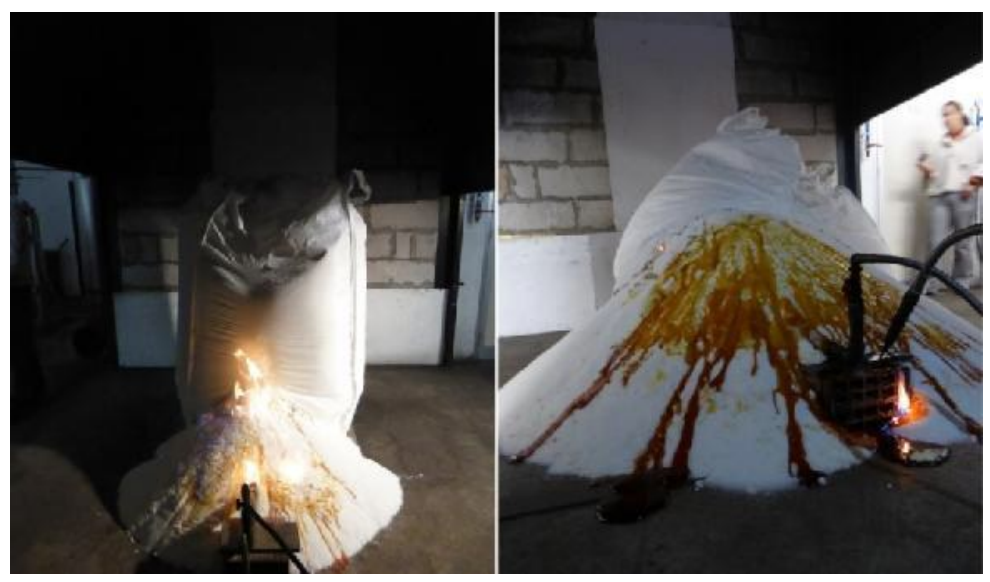

Fig. 12. Pictures of the real scale test for the $1000 \mathrm{~kg}$ sugar bag

By observing Fig. 11A, it is possible to observe that the fire was about to extinguish at about 180s. The transmittance has a minimum equal to $99 \%$.In the case of the stack of sugar sacks, each sack contains $50 \mathrm{~kg}$, with dimensions 40 x $82 \times 14.5 \mathrm{~cm}^{2}$. Fig. 13 displays 
the RHR and the transmittance for the experiment, and Fig. 14 shows some pictures of the process.

A
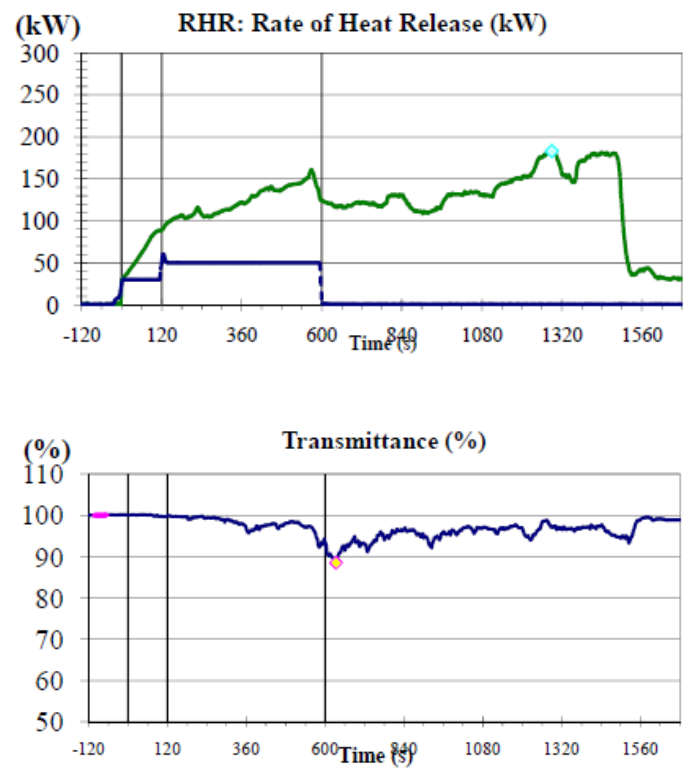

$\mathrm{B}$

Fig. 13. Results of the real scale test for the sugar stack (A: RHR, B: Transmittance)

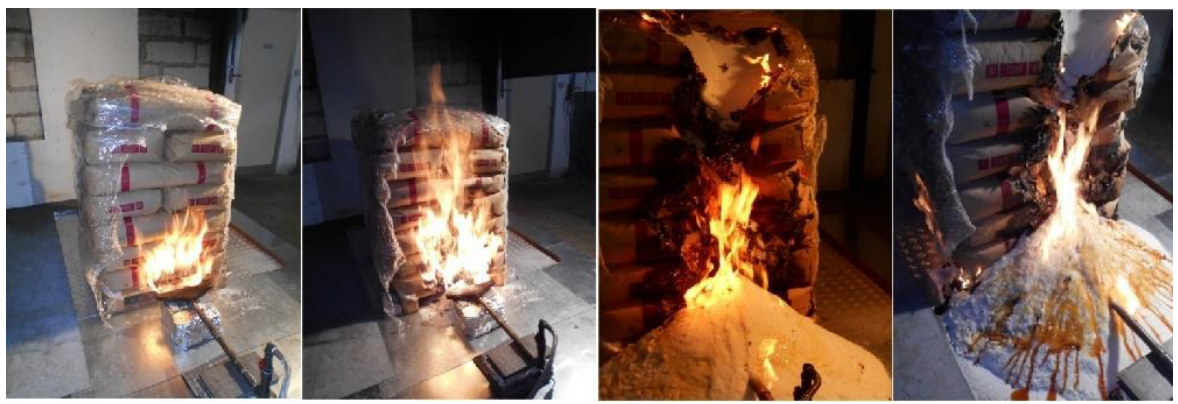

Fig. 14. Pictures of the real scale test for the sugar stack

In this case, we have a higher RHR peak $(183 \mathrm{~kW})$, and a lower transmittance minimum (89\%), providing evidence of more severe combustion in comparison with the single sugar bag.

As we can notice from the results, the first type of stock (1000 kg bag of sugar), the RHR is remarkably lower, reaching values close to 0 at about $180 \mathrm{~s}(35 \mathrm{~kW}$ peak, excluding the burner contribution). The second test, which has basically the same amount of sugar, but a different packaging, led to a more severe combustion process, with a consistent RHR over time (183 kW peak, excluding the burner contribution). Smoke production also was different, going from a $99 \%$ transmittance to a minimum of $89 \%$ in the second case.

\section{Conclusions}

In this work, fire safety issues of a wide range of materials have been investigated. The analyses performed were aimed at the estimate of values such as Calorific Values, THR, 
RHR and smoke analysis. Real-scale experiments have been also carried on, with the aim of addressing the combustion of materials stocked in warehouses. It was interesting to show that, theoretical values (such as calorific values) not always provide a good match with experimental results. Such discrepancies can be related to the fact that theoretical models cannot include specific characteristics of a good, like specific industrial recipes, presence of additives, different type of packages, that are extremely complex to integrate into such systems. This highly remarks the importance of specific experimental tests, in order to have values the most reasonable as possible. About the real-scale tests, we found evidence that, despite the great quantities involved in industrial storages, in case of fire, a small amount of the total mass appears to be involved in the process (all results lead to a combusted mass lower than $5 \%$ of the total). In the analysis on industrial rollers, the high compactness of the goods leads to a surface fire, rarely including the core of the roller. In the case of sugar, two different storage setups have been studied, showing that a big bag of sugar is inherently safer than a stack of smaller sacks (for a total $1000 \mathrm{~kg}$ of sugar in both cases), highlighting the importance of choosing the right storage strategy in order to improve safety. Finally, the results of these real-scale tests lead also to milder fire prevention and protection measures, in comparison with the results of pure theoretical models, which assume, extremely conservatively, the total combustion of the considered material.

Acknowledgements: All the experimental data dealing with measurments of products in real store conditions were provided by L.S. Fire Testing Institute s.r.1.. The experimental campaign, for all the mentioned cases, was lead to inform the Authorities of the real fire behaviour of products in storages, in order to obtain the Fire Prevention Certificate. Thanks to the Research Director, Dr. Silvio Messa, to his Assistant Director, D.ssa Eleonora Anselmi and to Dr. Alberto Taccori for the experimental researches conducted at the LS Fire laboratory.

\section{References}

1. E.C. Rada, G. Passamani, M. Ragazzi, V. Torretta, I.A. Istrate, I.A., G. Cioca, Dioxin contamination after a hypothetical accidental fire in baled municipal solid waste storage, Rev. Chimie 69, 997 (2018)

2. E. Trulli, E.C. Rada, F. Conti, N. Ferronato, M. Raboni, L. Talamona, V. Torretta, Fire simulation in a full-scale bilevel rail car: Experimental analysis to assess passenger safety, Int. J. Saf. Sec. Engineer. 8, 110 (2018).

3. C.S. Cattaneo, S. Tavelli, M. Derudi, R. Rora, M. Raboni, V. Torretta, S. Copelli, Study of a nimble model to evaluate the effects of a gasoline fire in a road tunnel, Chem. Engineer. Trans. 36, 337 (2014)

4. L.I. Cioca, R.I Moraru, R.I., Explosion and/or fire risk assessment methodology: A common approach, structured for underground coalmine environments, Arch. Min. Sci. 57, $53(2012)$

5. S. Scotland, Practical Fire Safety Guidance for Factories And Storage Premise, Scottish Government (2008)

6. International Fire Engineering Guidelines. Australian Building Codes Board, Canberra, Australia (2005)

7. K. Hon-leung Wong, D. Xie, Fire Safety Management Strategy of Complex Developments, Procedia Engineer. 71, 410 (2014)

8. I.L. Balan, L. Cioca, V. Torretta, L. Talamona, Warehouse Threats and Loss Prevention Management in Case of Fire, Procedia Technol. 22, 1028 (2016)

9. P. Dinenno, D. Drysdale, C. L. Bayler, W. D Walton, R. L. P. Custer, J. R. Hall Jr., J. M. Watts Jr., SFPE Handbook of Fire Protection Engineering (National Fire Protection Association, Quincy, 2008)

10. SFPE Engineering Guide to Performance-Based Fire Protection, 2nd Edition, National Fire Protection Association, Quincy, MA (2007) 
11. BS 7974, Application of Fire Safety Engineering Principles to the Design of Buildings, Code of Practice. British Standards Institute, London (2001)

12. Recommendations for a Model Curriculum for a BS Degree in Fire Protection Engineering, Society of Fire Protection Engineers, Bethesda, MD (2010)

13. M. J. Hurley, E. R. Rosenbaum, Performance-Based Fire Safety Design (CRC Press, Boca Raton, 2015)

14. N. Hofstra, B. Petkova, W. Dullaert, G. Reniers, S. de Leeuw, Assessing and facilitating warehouse safety, Saf. Sci. 105, 134 (2018)

15. D.M.I. 9-3-2007: Prestazioni di resistenza al fuoco delle costruzioni nelle attività soggette al controllo del Corpo Nazionale dei Vigili del Fuoco, Italy (2007)

16. Lettera Circolare n. 414/4122 sott. 55 del 28-3-2008: DM 9 marzo 2007 - Prestazioni di resistenza al fuoco delle costruzioni nelle attività soggette al controllo del CNVVF. Chiarimenti ed indirizzi applicativi, Italy (2008)

17. UNI EN 1991-1-2: Basi di calcolo e azioni sulle strutture - Azioni sulle strutture esposte al fuoco, Italy (1991)

18. A. H. Buchanan, A. K. Aku, Structural Design for Fire Safety (John Wiley \& Sons, 2017).

19. Comportamento al fuoco dei materiali, dei componenti costruttivi e degli arredi, ANIA (Associazione Italiana fra le Imprese Assicuratrici), Edizione 1986 (1986)

20. ISO 1716:2002, Reaction to fire tests for building products - Determination of the heat of combustion (2002)

21. ISO 5660:2015, Reaction-to-fire tests - Heat release, smoke production and mass loss rate Heat release rate (cone calorimeter method) and smoke production rate (dynamic measurement) (2015)

22. ISO 9705-1:2016, Reaction to fire tests - Room corner test for wall and ceiling lining products - Part 1: Test method for a small room configuration (2016)

23. BS EN 45545-1:2013, Railway applications. Fire protection on railway vehicles. General (2013)

24. EN 50399:2011, Reaction to fire test, Common test method for cables under fire conditions - Heat release and smoke production measurement on cables during flame spread test (2011) 